Rochester Institute of Technology

RIT Scholar Works

5-31-2019

\title{
An Orientation Program for Vertical Transfers in Engineering and Engineering Technology
}

\author{
Surendra K. Gupta \\ Rochester Institute of Technology \\ Franz Allen Foltz \\ Rochester Institute of Technology \\ James E. Moon \\ Rochester Institute of Technology \\ Roy W. Melton \\ Rochester Institute of Technology \\ Michael E. Kuhl \\ Rochester Institute of Technology
}

See next page for additional authors

Follow this and additional works at: https://scholarworks.rit.edu/other

\section{Recommended Citation}

Gupta, S. K., \& Foltz, F. A., \& Moon, J. E., \& Melton, R. W., \& Kuhl, M., \& Johnson, D. P., \& Lee, J., \& Garrick, R., \& Valentine, M. S. (2019, June), An Orientation Program for Vertical Transfers in Engineering and Engineering Technology Paper presented at 2019 ASEE Annual Conference \& Exposition , Tampa, Florida. 10.18260/1-2--32084

This Conference Proceeding is brought to you for free and open access by the Faculty \& Staff Scholarship at RIT Scholar Works. It has been accepted for inclusion in Presentations and other scholarship by an authorized administrator of RIT Scholar Works. For more information, please contact ritscholarworks@rit.edu. 
Authors

Surendra K. Gupta, Franz Allen Foltz, James E. Moon, Roy W. Melton, Michael E. Kuhl, Daniel Johnson, James Lee, Robert D. Garrick, and Maureen Valentine 


\section{An Orientation Program for Vertical Transfers in Engineering and Engineer- ing Technology}

\section{Dr. Surendra "Vinnie" K. Gupta, Rochester Institute of Technology (COE)}

"Vinnie" Gupta is a professor of mechanical engineering, and a member of the graduate faculty of materials science and engineering at the Rochester Institute of Technology (RIT), Rochester, NY. He is a recipient of the 2014 Robert G. Quinn Award from ASEE, and the 2000 Eisenhart Award for Outstanding Teaching. At RIT, he teaches undergraduate and graduate courses in applied mechanics, computational techniques, and materials science.

\section{Prof. Franz Allen Foltz, Rochester Institute of Technology}

Franz Foltz is an associate professor with dual appointments in the Departments of Science, Technology and Society and Public Policy at the Rochester Institute of Technology (RIT), Rochester, NY. He is the Director of the Graduate Program in Science, Technology and Public Policy. At RIT, he teaches undergraduate and graduate courses in Science and Technology Policy, Research Design, and Policy Analysis.

\section{Dr. James E Moon, Rochester Institute of Technology (COE)}

James Moon, Rochester Institute of Technology James Moon is a Professor in the Electrical and Microelectronic Engineering department. He was a recipient of the 2009 Eisenhart Award for Excellence in Teaching. At RIT, he teaches undergraduate and graduate courses primarily in semiconductor device physics, solid-state physics, and electronics.

\section{Dr. Roy W Melton, Rochester Institute of Technology (COE)}

Roy Melton is Principal Lecturer in the Department of Computer Engineering of the Kate Gleason College of Engineering (KGCOE) at the Rochester Institute of Technology (RIT) in Rochester, N.Y. His awards and honors include KGCOE Award for Exemplary Performance in Teaching (2017 and 2014), selection as "most effective teacher" by RIT Computer Engineering classes of 2017, 2015, 2013, 2012, 2011, and 2010, and finalist for the 2015-2016 and 2012-2013 RIT Outstanding Teaching Award for NonTenure-Track Faculty. He received his Ph.D., M.S.E.E., and B.E.E. degrees from the Georgia Institute of Technology in Atlanta, Ga. His memberships include ASEE and IEEE (Senior Member).

\section{Dr. Michael Kuhl, Rochester Institute of Technology (COE)}

Michael E. Kuhl, $\mathrm{PhD}$ is a Professor in the Department of Industrial and Systems Engineering at Rochester Institute of Technology. He earned his PhD in Industrial Engineering in 1997 from North Carolina State University. His research and teaching interests are in simulation, operations research, and decision analysis with a wide range of application areas including intelligent material handling systems, healthcare systems, project management, cyber security, and supply chain systems.

\section{Prof. Daniel P. Johnson, Rochester Institute of Technology (CET)}

Daniel Johnson is a Professor Chair of the Department of Packaging Science in the College of Engineering Technology at RIT. He teaches courses in production and supply chain management, manufacturing operations, automation, robotics, and operations strategy.

\section{Dr. James Lee, Rochester Institute of Technology (CET)}

James H. Lee is an associate professor at the Rochester Institute of Technology. His areas of research expertise include internal combustion engines, renewable fuels, the design and implementation of sustainable energy systems, and technical and economic analysis of system upgrades to improve energy efficiency. Dr. Lee is a professional engineer licensed in the state of New York.

\section{Dr. Rob Garrick, Rochester Institute of Technology (CET)}


Robert D. Garrick, Ph.D., P.E., is a Professor in the Department of Manufacturing and Mechanical Engineering Technology at the Rochester Institute of Technology (RIT) and Department Chair. Garrick worked for 25 years in automotive engineering research and holds seven U.S. patents.

\section{Prof. Maureen S. Valentine, Rochester Institute of Technology (CET)}

Maureen Valentine, P.E., Professor, has been a faculty member at RIT for more than 25 years, serving as instructional faculty, department chair for the Department of Civil Engineering Technology, Environmental Management, and Safety, associate dean of the College of Applied Science and Technology and co-PI on the AdvanceRIT initiative. Her scholarly activities recently have focused on women in STEM programs and the women faculty who teach them. 


\title{
An Orientation Program for Vertical Transfers in Engineering and Engineering Technology
}

\begin{abstract}
This paper reports on a scholarship program funded by the National Science Foundation that focuses on students who transfer at the $3^{\text {rd }}$-year level from 2-year schools to the engineering and engineering technology BS programs at our university. The objectives of the program are to: (i) expand and diversify the engineering/technology workforce of the future, (ii) develop linkages and articulations with 2-year schools and their S-STEM (Scholarships in Science, Technology, Engineering and Mathematics) programs, (iii) provide increased career opportunities and job placement rates through mandatory paid co-op experiences, and (iv) serve as a model for other universities to provide vertical transfer students access to the baccalaureate degree.
\end{abstract}

The program is in its third year. It recruited its first group of 25 students in Fall 2017, and another group of 27 students in Fall 2018. We hope to recruit 26 more students in Fall 2019 for a total of 78 vertical transfers. The goal is to retain and graduate at least $95 \%$ of these scholars.

To enhance the success of these scholars, a zero-credit six-week orientation course was developed in Fall 2017 focusing on four dimensions of student wellness: academic, financial, social, and personal. This paper describes the development of this course, its content, and the modifications that were made to the course for Fall 2018.

The paper will also address the research conducted in order to generate knowledge about the program elements that will be essential for the success of vertical transfer programs at other universities. Two research instruments are described: an online survey and a focus group interview that were developed, and administered to the transfer scholars in their first year. Initial findings concerning students' experiences at their 2-year schools, their reason for transferring, their experience in transferring as well as their initial conceptions of what life at a 4-year institution will be like are presented.

\section{Introduction}

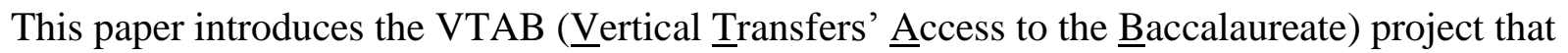
focuses on students who transfer at the $3^{\text {rd }}$ year level from 2-year schools to the engineering and engineering technology BS programs at our university. The objectives of this project are: (i) to expand and diversify the engineering/technology workforce of the future, (ii) to develop linkages and articulations with 2-year schools and their S-STEM programs, (iii) to provide increased career opportunities and job placement rates through mandatory paid co-op experiences, and (iv) to serve as a model for other universities to provide vertical transfer students access to the baccalaureate degree.

VTAB project is funded by a five-year grant from the National Science Foundation (NSF) that began in September 2017. In its program solicitation [1], NSF stated its goals to be: (i) to 
increase the number of low-income academically talented students in STEM, (ii) to improve the education of these STEM students, and (iii) to generate knowledge to advance understanding of factors that lead to the success of these students. VTAB is leveraging the lessons learned from an earlier TiPi (Transfer Pipeline) project to achieve the first two goals [2]. The third goal is addressed later in the section that describes the online surveys and focus group interviews. The TiPi project began in June 2012 funded by a four-year grant of $\$ 599,984$ from NSF. It provided scholarship support of $\$ 8,000$ to 75 students who transferred from a 2-year school to a BS degree program in engineering or engineering technology at our university. Of the 75 TiPi scholars, only $4(5 \%)$ left our university, and the remaining $71(95 \%)$ graduated with at least a BS degree.

The lessons learned from the TiPi project were that (i) recruiting 25 low-income students per year is challenging, (ii) the university transfer orientation program can be improved considerably, (iii) individualized advising and academic monitoring is very effective in retaining scholars, (iv) academic performance of the scholars is similar or better than their peers, (v) scholars had no difficulty in obtaining meaningful paid co-op employment, and employers reported their performance to be satisfactory, (vi) all graduated scholars have placements in industry or graduate schools, and (vii) encouraged by this project's success, two more engineering departments began accepting vertical transfers from 2-year schools, and are now participating in this VTAB project.

\section{VTAB - Vertical Transfers' Access to the Baccalaureate in Engineering and Engineering Technology}

The VTAB project is a collaborative effort of eight academic departments from two colleges, the Enrollment Management and Career Services Division, and the Office of Financial Aid and Scholarships. Table 1 lists the participating departments in column 2, and their BS degree offerings in column 3 .

\begin{tabular}{|c|c|c|}
\hline \multicolumn{3}{|c|}{ Table 1: Participating Colleges, Academic Departments, and Degree Programs } \\
\hline College* & Academic Department & BS Program in \\
\hline \multirow[b]{2}{*}{ CET } & \multirow{2}{*}{$\begin{array}{l}\text { Civil Engineering Technology and } \\
\text { Environmental Management and Safety } \\
\text { (CET-EMS) }\end{array}$} & Civil Engineering Technology \\
\hline & & $\begin{array}{l}\text { Environmental Sustainability, Health, } \\
\text { and Safety }\end{array}$ \\
\hline \multirow{3}{*}{ CET } & \multirow{3}{*}{$\begin{array}{l}\text { Electrical, Computer, and } \\
\text { Telecommunication } \\
\text { Engineering Technology (ECTET) }\end{array}$} & Electrical Engineering Technology \\
\hline & & Computer Engineering Technology \\
\hline & & $\begin{array}{l}\text { Telecommunication Engineering } \\
\text { Technology }\end{array}$ \\
\hline \multirow{2}{*}{ CET } & \multirow{2}{*}{$\begin{array}{l}\text { Manufacturing/Mechanical Engineering } \\
\text { Technology (MMET) }\end{array}$} & Manufacturing Engineering Technology \\
\hline & & Mechanical Engineering Technology \\
\hline CET & Packaging Science (PS) & Packaging Science \\
\hline \multirow{2}{*}{$\mathrm{COE}$} & \multirow{2}{*}{$\begin{array}{l}\text { Electrical and } \\
\text { Microelectronic Engineering (EME) }\end{array}$} & Electrical Engineering \\
\hline & & Microelectronic Engineering \\
\hline $\mathrm{COE}$ & Mechanical Engineering (ME) & Mechanical Engineering \\
\hline
\end{tabular}




\begin{tabular}{|l|l|l|}
\hline $\mathrm{COE}$ & Industrial \& Systems Engineering (ISE) & Industrial Engineering \\
\hline $\mathrm{COE}$ & Computer Engineering (CE) & Computer Engineering \\
\hline
\end{tabular}

${ }^{*} \mathrm{CET} \equiv$ College of Engineering Technology; $\quad * \mathrm{COE} \equiv$ College of Engineering

Collectively, the eight departments listed in Table 1 offer thirteen BS degree programs that are five-year programs with a mandatory cooperative education component wherein students attend classes in Fall and Spring semesters in their first two years. During the third and fourth years, students alternate between on-campus study and off-campus co-op employment in industry. All students must complete at least 48 weeks of paid co-op employment. Each student finds co-op employment with help from an assigned co-op coordinator in the Office of Cooperative Education and Career Services.

Utilizing a comprehensive longitudinal dataset containing a census of every public high school student in the state of Florida, a recent 2015 study [3] concludes that (i) 2-year college transfer students are sensitive to distance often choosing the nearest 4-year institution; (ii) if the nearest 4-year institution is far away, students do not transfer at all; and (iii) low-income students often transfer to the nearest 4-year institution despite the fact that it may have fewer resources and low graduation rates. So, a 4-year private institution must cast a wider net - say contact all 2-year colleges in a 300 mile radius (a day trip by car), - and must find novel ways to reach potential transfer students and their families.

Using data from the National Student Clearinghouse on a cohort of more than 700,000 degreeseeking students, the Community College Research Center at Columbia University recently reported [4] that transfer students at very selective 4-year institutions had higher graduation rates than all other institutions: $52 \%$ for low-income versus $60 \%$ for high-income students. The report asks the state policymakers to encourage the very selective institutions to enroll more transfer students from 2-year colleges. At our university, the graduation rate of vertical transfers is about $77 \%$, and was $95 \%$ for vertical transfers in the NSF supported TiPi program mentioned earlier [2].

VTAB project is in its third year. It recruited its first group of 25 students in Fall 2017, and another group of 27 students in Fall 2018. We hope to recruit 26 more students in Fall 2019 for a total of 78 vertical transfers. The goal is to retain and graduate a minimum of $95 \%$ of these scholars.

From 2007 to 2010, the Jack Kent Cooke Foundation (JKCF) funded 8 highly selective 4-year institutions to enroll 1,100 high-achieving low-income to moderate-income transfer students [5]. 97\% of these Cooke Transfer Scholars earned their baccalaureate degree in three years [6]. These scholars were selected from a pool into which each 2-year college nominated its best two students which might explain the $97 \%$ success rate. Nevertheless, there are proven strategies to increase graduation rates among vertical transfers.

By following 111 high-achieving low-income transfer students in the JKCF program, a recent research study [7] identified challenges faced by these students, and classified them into four broad categories: (i) Academic (managing academic load, obtaining good grades, being a strong 
student); (ii) Social (fitting in and making friends, finding a study group, finding suitable extracurricular activities); (iii) Financial (paying for school and living expenses); and (iv) Personal (leaving family and home community, mental or physical health). Thus, a vertical transfer program must address these four issues to be successful.

Our university offers an option of either a short (half-day) or a long (two-day) orientation program to all the incoming transfer students. To focus on the needs of VTAB scholars, the project administrator created and taught a zero-credit VTAB Orientation course that met for 50 minutes each week for the first six weeks of the Fall semester. In the first five weeks, the course instructor arranged to have local experts conduct workshops focusing on academic integration [8], social integration [9], financial discipline [10], and personal well-being [11]. At the end of the course, we had a Friday social with pizza and cookies, and the external evaluator invited a group of scholars for a focus group interview.

Twenty of the 25 scholars responded to the semester-end course evaluation survey in Fall 2017. $90 \%$ or more respondents found the course to be well organized, and that it advanced student understanding. Based on their feedback, in Fall 2018, the course instructor invited a student guest to each workshop to offer tips for success and answer questions. The pairing of a student with the workshop expert each week was very successful. Seventeen of the 27 scholars responded to the semester-end course evaluation survey. Again, $90 \%$ or more respondents found the course to be well organized, helpful, and effective in achieving its objectives.

From the first cohort (2017) of 25 scholars, the number of students who obtained paid full-time co-op employment in industry was 15, 22, and 5 in Spring, Summer, and Fall terms of 2018 respectively. One scholar participated in a study-abroad program last summer. We have had $100 \%$ retention in the first cohort.

\section{Online Survey and Focus Group Interview}

A 28-question online survey with free comment space was designed with a few questions adapted from past surveys [5, 12-14]. The survey was organized to examine the participants' experiences at their 2-year schools, and their experiences during the transfer process, as well as their experiences while enrolling at our university. 23 out of 25 scholars from the first cohort (2017), and 23 out of 27 scholars from the second cohort (2018) responded to the survey. Additional surveys will be administered throughout the scholars' experience that will build on this first survey, and provide a complete picture of their experience in the VTAB project. The second survey, which will explore the students' experience at RIT midway through their studies will be sent to the first cohort this spring.

The second cohort survey results were very similar to those of the first cohort. The most interesting results from this survey came in the section concerning their 2-year programs as they support the need of the VTAB grant. Most of the students always planned to go to a 4-year school after completing their 2-year program (22 out of 23 respondents or $96 \%$ of the second cohort, which was almost identical to the 22 out of 24 respondents or $92 \%$ for the first cohort). Question \#5 of the online survey asked, "What were your main reasons for enrolling in the 2- 
Year school instead of a 4-Year college or university? (Check all that apply): (a) Academic reasons, (b) Financial reasons, (c) Personal reasons, and (d) Other reasons." Figure 1 presents a bar chart of responses to this question from each of the two cohorts.

What were your main reasons for enrolling in the 2-year school instead of a 4-year college or university? (Check all that apply)

First Cohort (2017)

Second Cohort (2018)

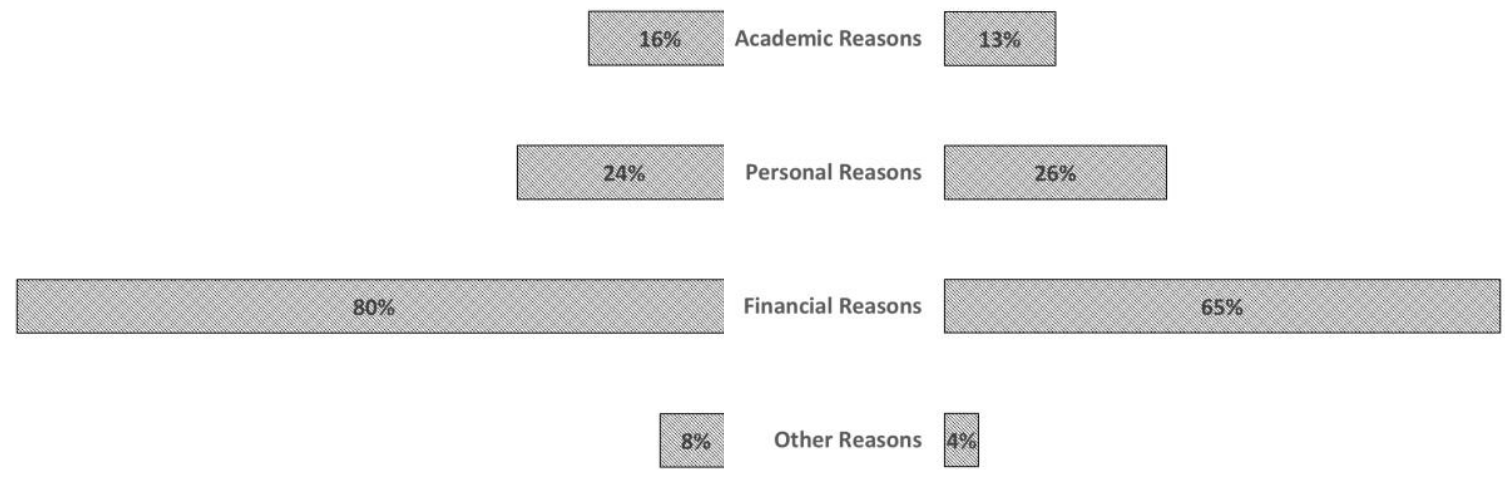

Figure 1: Main reasons for enrolling in a 2-year school before transferring to a 4-year college

Once again, as one would expect, the biggest issue for their going to a 2-year school initially was financial. For the second cohort 15 out of 23 or $65 \%$ listed financial concerns as one of their main reasons for enrolling initially in the 2-year school. For the first cohort the result was 20 out of 25 respondents $(80 \%)$. The combined result for both cohorts was 35 out of 48 or $72 \%$ of the students initially enrolled at a 2-year school for financial reasons. The major difference between the two cohorts was that for the first cohort half of those responding said that their biggest challenge while at the 2-year school came from family issues, while for the second cohort only a third thought their family was a challenge, and over $80 \%$ thought the stress of balancing class and work was a significant challenge.

Once again, there were very few concerns overall raised about the transfer application process. Since our university has a long history with transfer students and most 2-year schools routinely transfer students to 4-year ones, these findings would be expected. Findings on students' perceptions of the admission and financial aid application processes are presented in Figures 2 and 3.

Figure 2 presents a diverging bar chart of responses to Question \#15 about the transfer application process from each of the two cohorts:

(15a) Availability of good information about transfer requirements;

(15b) Availability of advising and counseling about the transfer requirements;

(15c) Availability of advising and counseling about the transfer process;

(15d) Ease of completing transfer documents;

(15e) Assistance in filling out our university's admission application;

(15f) Timeliness in informing you about your admission to our university;

$(15 \mathrm{~g})$ Timeliness in informing you about the academic credits transferred to our university; 
(15h) Access to an Academic Advisor in your major at out university.

How would you rate our university with respect to each of the following aspects of your transfer application process?

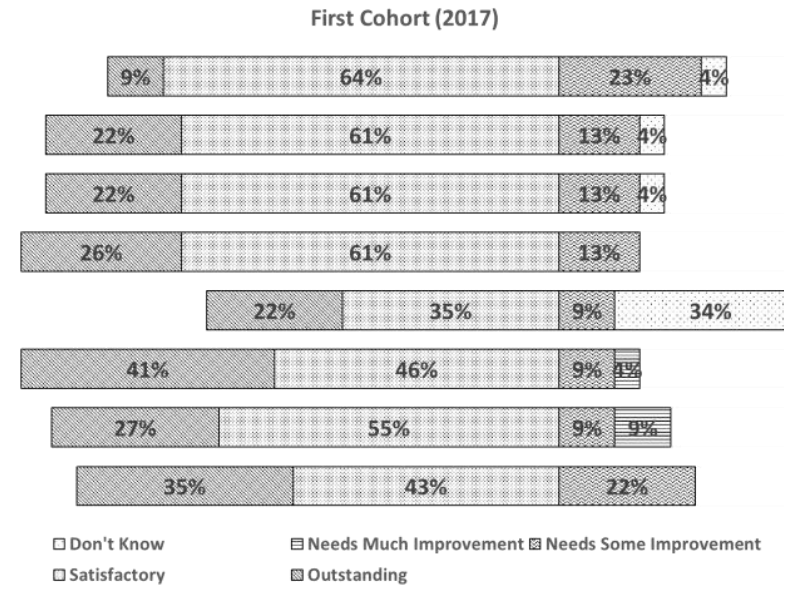

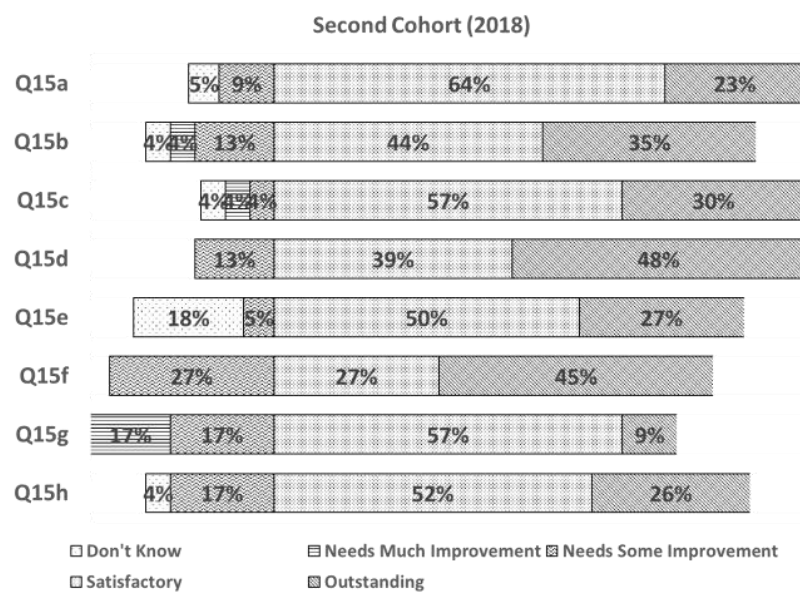

Figure 2: Responses to survey question about the transfer application process

Figure 2 shows that once again overall students are satisfied with the transfer application process, although there is definitely still some room for improvement. Once again a couple of students thought that the timeliness of the information needed much improvement, while a few students thought that some improvement was needed in every category. However, there was a big improvement in the number of students who were uncertain about assistance with filling out the university admission application. This dropped by 50\%, from $34 \%$ to $17 \%$. This decrease probably meant that more had some help with the admission application process.

Figure 3 presents a diverging bar chart of responses to Question \#16 about the financial aid process from each of the two cohorts:

(16a) Availability of good information about financial aid available;

(16b) Communication with the Office of Financial Aid and Scholarships;

(16c) Timeliness in informing you about your financial aid package;

(16d) Level of financial aid offered by our university. 
How would you rate our university with respect to each of the following aspects of your financial aid application process?

First Cohort (2017)

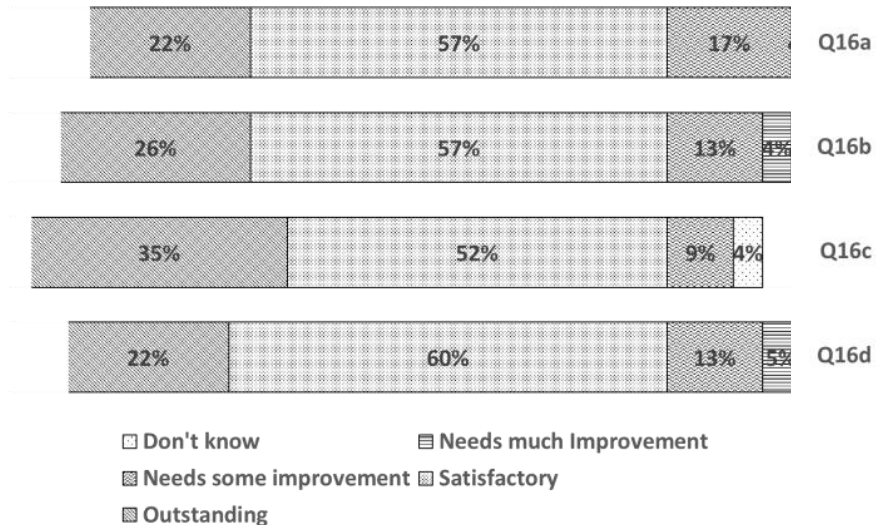

Second Cohort (2018)
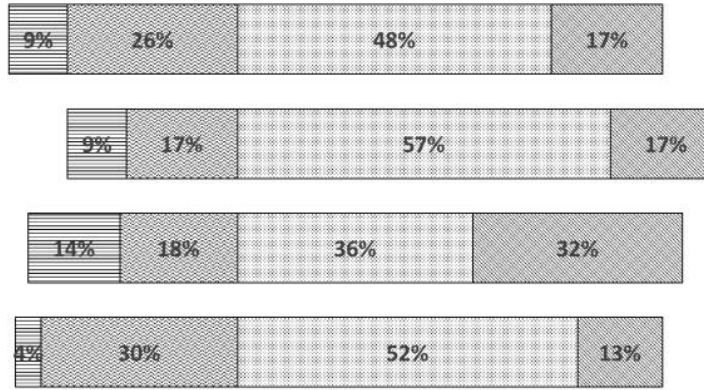

目 Needs much Improvement 图 Needs some improvement $\square$ Satisfactory $\square$ Outstanding

Figure 3: Responses to survey question about the financial aid process

Figure 3 shows that students were overall satisfied with the financial aid application process though there were some minor issues with some of the scholars concerning the financial aid process. There were a few more dissatisfied with the process this year than last year. It appears that a couple of students had some major issues across the board and few thought it needed some improvement. Unfortunately, the process is outside of our control to change. However, overall it seems to be working fairly well.

Question \#22 of the online survey asked, "What were your main reasons for enrolling in our university? (Check all that apply). Figure 4 presents a bar chart of responses to this question from each of the two cohorts.

(22a) The university offered the major I was interested in.

(22b) The university is close to my home.

(22c) The university provides student housing.

(22d) The university provided me an attractive financial aid package.

(22e) The university has a mandatory co-op program.

(22f) The university accepted all or most of 2-year College courses for transfer credit.

(22g) I have a lots of friends who attend the university.

(22h) The university has a great reputation.

(22i) Other, please specify. 
What were the main reasons for enrolling in our university? (Check all that apply)
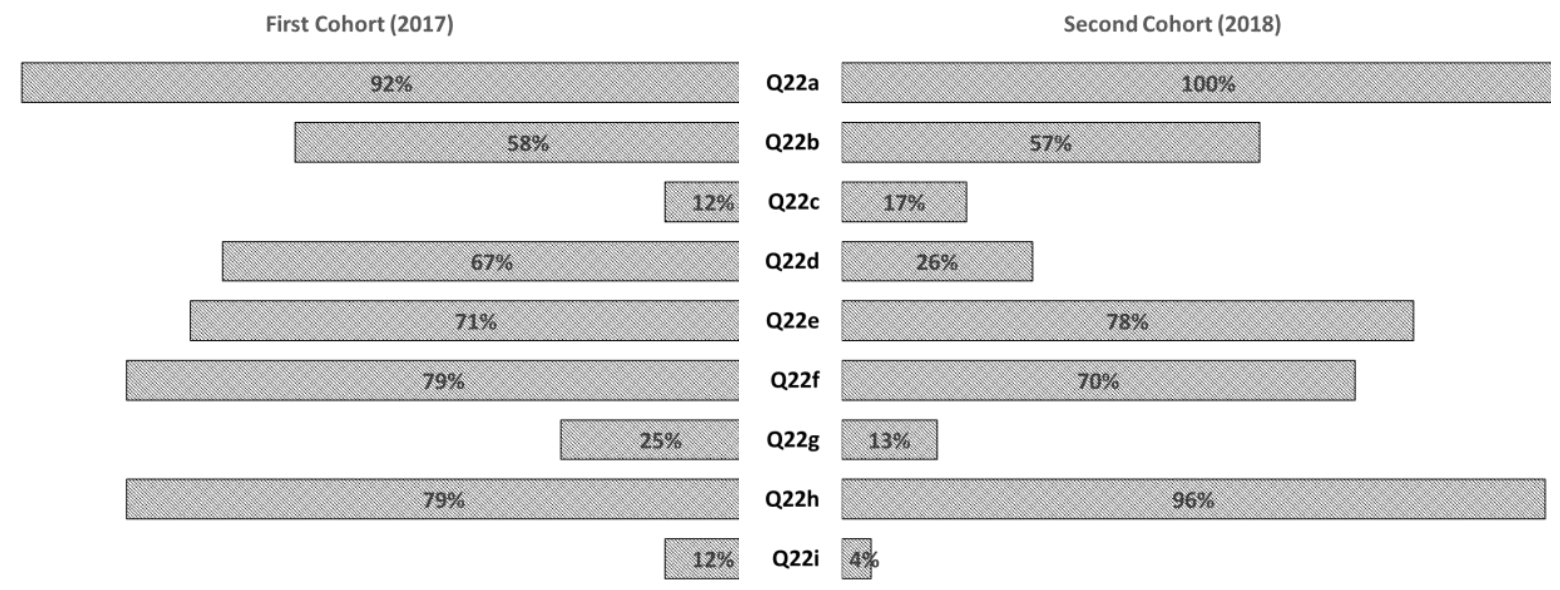

Figure 4: Main reasons for enrolling in our university

Figure 4 shows that the scholars chose to enroll in our university because it offered the major of their interest, has a mandatory co-op program, accepted all or most of their course credits for transfer, and has a great reputation. A similar question asked in the focus group interview conducted a few weeks later corroborated the survey findings. In the focus group, scholars also mentioned that they chose our university because of its hand-on curriculum, high graduation rate, and nearly $100 \%$ after-graduation placement in industry or graduate schools.

The role of NSF scholarship in transfer enrollments is much harder to analyze because it is a small but significant part of a student's entire financial aid package. We hope that with this scholarship support, the need for any paid non-curricular work is eliminated or significantly reduced. We learned this from the TiPi project mentioned earlier [2]. The VTAB project focuses only on income diversity among our undergraduate population. None of project goals focus on gender or ethnic diversity.

The final section on their early experiences at our university were generally positive with very few issues raised at this point. One reason for this was that their experiences with our university was very new to them at that point, and the additional surveys will hopefully illuminate their experiences more. For our purposes the most useful finding was that once again only a little over half (52\% for cohort 2 , statistically similar to the $57 \%$ for cohort 1 ) attended the university orientation program, and $71 \%$ of those found it useful, (again basically identical to the $69 \%$ for the first cohort). This was the generic university program, and not an orientation program specifically designed for VTAB scholars, though the focus group provided more useful information.

Once again the focus group protocol was developed based on the results of the survey, and a group of scholars were interviewed at the conclusion of the orientation course. The focus group findings basically corroborate the survey findings. Particularly interesting for our project was that the responses were generally positive when asked about our specifically designed orientation course. One response in particular was: 
So what I liked about it is that my twin sister transferred to RIT last spring and I told her some things that I learned from the program and there's things that I was telling her that she didn't even know, and she's been at RIT already for a year now. So there's like a ... little things that maybe not all students would know. But since we were in this program, we learned about the food storage and how to make appointments and things that you wouldn't learn in the orientation that we learned through this class.

During the focus group, students also made some suggestions for future improvement. Suggestions include:

1. Students wish the program team could do something to get them more involved so that they could know each other a little bit more, and they could help each other.

2. Students wish to have more interactions during the classes.

3. Students wish to receive an earlier notice about this scholarship in order to plan their schedule in advance.

\section{Future Plans}

We hope to recruit 26 new VTAB scholars from 2-year schools in Fall 2019 for a total of 78 scholars. Based on the feedback from past semesters, we will improve the VTAB Orientation course for the new cohort \#3. The new cohort will be administered the online survey, and will be asked to participate in the focus group interview.

We hope to retain and graduate at least $95 \%$ of these 78 scholars. When the project is over, institutionalizing and sustaining this vertical transfer program for low-income students at our university will require both human and financial resources. Human resources such as designating a faculty member in each participating department to evaluate transfer transcripts and to advise transfer students already exist, and will continue after this project is over. A coordinator, preferably one from each of the two participating colleges, will be needed who can champion for high-achieving low-income transfer students, and coordinate the recruiting efforts among the departments, Admissions, and Financial Aid. The ideal person will likely be the Associate Dean for Undergraduate Studies in each of the two colleges. Financial resources will be required to support the additional financial need of low-income transfer students. Our university excels in raising funds as endowments for such a worthy cause. Thus, we are confident that the vertical transfer program for low-income students can be institutionalized and sustained at our university after the project period is over.

\section{Acknowledgements}

This work was supported in part by the National Science Foundation under award numbers DUE-1154027 and DUE-1643703. Help from Ms. Deanne Pettinelli in administering the financial aid is gratefully acknowledged. 


\section{References}

1. Program Solicitation, "Scholarships in Science, Technology, Engineering, and Mathematics (SSTEM)", NSF 16-540, National Science Foundation, 2016.

2. S. K. Gupta, J. E. Moon, R. W. Melton, M. E. Kuhl, D. P. Johnson, T. Dunn, J. H. Lee, F. Foltz, and R. Garrick, "Scholarship Programs for Vertical Transfers in Engineering and Engineering Technology," Proceedings of the 2018 ASEE Annual Conference in Salt Lake City, UT (June 2018).

3. B. Backes and E. D. Velez, "Who Transfers and Where Do They Go? Community College Students in Florida," National Center for Analysis of Longitudinal Data in Education Research, Working Paper 124, February 2015.

4. D. Jenkins and J. Fink, "Tracking Transfer - New Measures of Institutional and State Effectiveness in Helping Community College Students Attain Bachelor's Degrees," Community College Research Center, Teachers College, Columbia University, January 2016.

5. C. Burack, S. Lanspery, T. P. Shields, and S. Singleton, "Partnerships That Promote Success: Lessons and Findings from the Evaluation of the Jack Kent Cooke Foundation's Community College Transfer Initiative," Brandeis University, MA, January 2014.

6. J. Giancola and E. Davidson, "Breaking Down Walls: Increasing Access to Four-Year Colleges for High-achieving Community College Students," Jack Kent Cooke Foundation, January 2015.

7. B. Schmertz and J. Carney, "Making the Leap: Understanding the Successful Transfer of Highachieving, Low-income Community College Students to Four-Year Institutions,” Jack Kent Cooke Foundation, October 2013.

8. https://www.rit.edu/studentaffairs/asc/

9. https://www.rit.edu/studentaffairs/orientation/

10. https://www.rit.edu/studentaffairs/criw/wellness-courses.php

11. https://www.rit.edu/studentaffairs/parent-and-family-programs

12. F. S. Laanan, "Beyond transfer shock: A study of students' college experiences and adjustment processes at UCLA", Doctoral Dissertation, University of California, Los Angeles, CA, 1998.

13. M. T. Peddle and C. E. Trott, "Transfer Student Satisfaction Survey", The Illinois Articulation Initiative, Final Report to the Illinois Board of Higher Education, Center for Governmental Studies, Northern Illinois University, IL, 2016.

14. X. Wang, "Upward Transfer in STEM Fields of Study: A new Conceptual Framework and Survey Instrument for Institutional Research", New Directions for Institutional Research, v170, p49-60, 2016. 